\title{
Fístula Bronco-Pleuro-Cutânea: Uma Manifestação Rara de Tuberculose Pulmonar
}

\author{
Bronchopleurocutaneous Fistula: A Rare Complication of Pulmonary \\ Tuberculosis
}

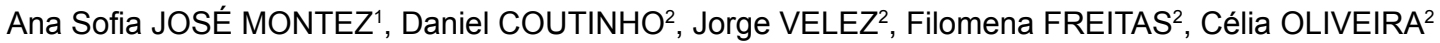 \\ Acta Med Port 2015 Mar-Apr;28(2):260-262
}

RESUMO

Introdução: A tuberculose pulmonar pode cursar com diversas complicações. As fístulas bronco-pleuro-cutâneas consistem em comunicações anormais entre o brônquio, o espaço pleural e a pele.

Caso Clínico: Apresentamos o caso de um homem, 47 anos, esquizofrénico, enviado ao Serviço de Urgência por toracalgia esquerda, tosse produtiva e emagrecimento. Apresentava-se caquético, sendo evidente um orifício cutâneo torácico latero-anterior esquerdo com drenagem purulenta, na qual o exame direto revelou bacilos ácido-álcool resistentes. A radiografia torácica evidenciava infiltrado heterogéneo bilateral. Foi internado com o diagnóstico de tuberculose pulmonar fistulizada. Na expetoração, a pesquisa de bacilos ácido-álcool resistentes foi igualmente positiva, sendo evidenciado Mycobacterium tuberculosis por reação de polimerase em cadeia e exame cultural. Iniciou terapêutica antituberculosa quádrupla apresentando evolução clínica favorável.

Conclusões: A formação de fístulas bronco-pleuro-cutâneas é atualmente e em países desenvolvidos, uma complicação rara de tuberculose pulmonar. Assim, apesar da tuberculose ser frequente em Portugal, a raridade deste tipo de complicações torna pertinente a apresentação deste caso clínico.

Palavras-chave: Doenças da Pleural; Fistula; Fístula Brônquica; Tuberculose Pulmonar.

\section{ABSTRACT}

Introduction: Multiple complications can occur in tuberculosis. Bronchopleurocutaneous fistula is a pathological communication between bronchus, pleural space and skin.

Clinical Case: We present a 47 year-old male patient, schizophrenic, who presented with complaints of pleuritic chest pain, cough and weight loss. The patient was cachectic with purulent drainage from an orifice in the antero-lateral left chest wall. In this drainage acidfast bacilli were identified and chest radiograph showed bilateral infiltrates. He was admitted to the Infectious Diseases Department with the diagnosis of fistulized pulmonary tuberculosis, confirmed by visualization of acid-fast bacilli, positive polymerase chain reaction and cultures for Mycobacterium tuberculosis in the sputum. The patient was started on quadruple antituberculosis therapy and had a favorable outcome.

Conclusions: Bronchopleurocutaneous fistula is a rare complication of pulmonary tuberculosis. Despite pulmonary tuberculosis being a common condition in our country, the rarity of this complication prompted the authors to present it.

Keywords: Bronchial Fistula; Fistula; Pleural Diseases; Tuberculosis, Pulmonary.

\section{INTRODUÇÃo}

A tuberculose é uma das doenças infeciosas mais prevalentes a nível mundial. São estimados anualmente 8,9 milhões de novos casos e 1,4 milhões de mortes no mundo. ${ }^{1} \mathrm{Na}$ Europa ocidental, Portugal é o país com uma das incidências mais elevadas $(21,64$ casos por 100000 habitantes). ${ }^{1}$

A infeção pelo Mycobacterium tuberculosis complex (Mt) tem um atingimento preferencialmente pulmonar, podendo existir envolvimento de outros órgãos em 1/3 dos casos.

O curso da doença depende da interação entre a resposta do hospedeiro e a virulência do microorganismo. A imunidade celular é a principal defesa do hospedeiro contra o bacilo da tuberculose. Existindo resposta de contenção granulomatosa eficaz ocorre resolução, embora possam persistir sequelas parenquimatosas, ganglionares ou pleurais. ${ }^{2}$ Nos casos em que a carga bacilar infetante não é contida pela resposta imunológica do hospedeiro pode ocorrer progressão local e disseminação à distância por via linfo-hematogénica. ${ }^{2,3}$ Assim, diversas sequelas e compli- cações podem surgir, tanto em doentes tratados como não tratados. ${ }^{4}$

O desenvolvimento de fístula bronco-pleuro-cutânea é uma complicação rara de tuberculose pulmonar, correspondendo a uma comunicação patológica entre os brônquios, o espaço pleural e a pele.

\section{CASO CLÍNICO}

Descrevemos o caso de um homem, 47 anos de idade, caucasóide, com antecedentes de esquizofrenia, enviado ao Serviço de Urgência (SU) por quadro constitucional, com queixas de toracalgia esquerda e tosse.

O quadro clínico tinha meses de evolução, embora tivesse sido impossível precisar pelas dificuldades na coIheita da anamnese. A clínica apresentada consistia num quadro constitucional caraterizado por anorexia e emagrecimento não quantificado, associado a toracalgia esquerda de caraterísticas pleuríticas e tosse com expetoração muco-purulenta, sem noção de febre.

1. Serviço de Medicina Interna. Centro Hospitalar do Baixo Vouga. Aveiro. Portugal.

2. Serviço de Infeciologia. Centro Hospitalar do Baixo Vouga. Aveiro. Portugal.

Recebido: 01 de Maio de 2014 - Aceite: 20 de Outubro de 2014 | Copyright @ Ordem dos Médicos 2015 


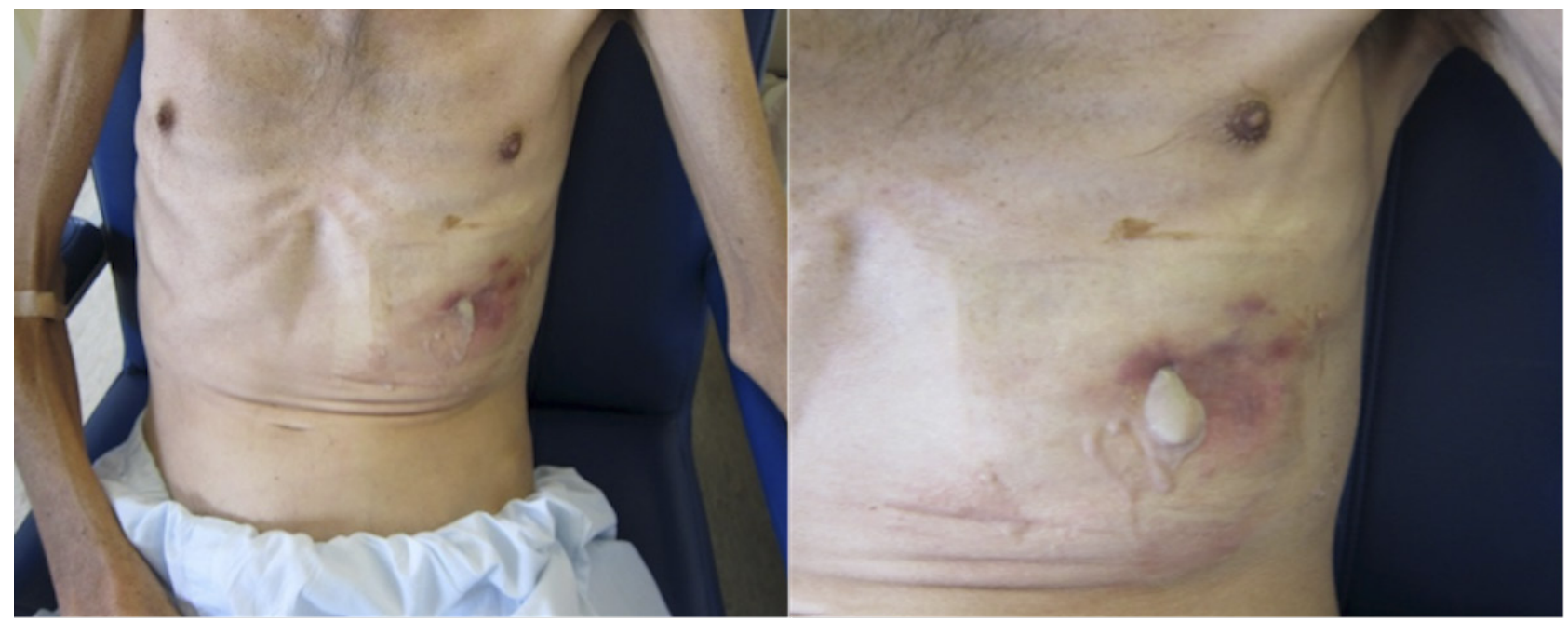

Figura 1 - Caquexia marcada e drenagem purulenta pelo orifício fistuloso na região torácica antero-inferior esquerda

Ao exame objetivo era notória caquexia marcada e a presença de um orifício cutâneo torácico latero-anterior esquerdo com drenagem purulenta (Fig. 1). O doente estava apirético, sem dificuldade respiratória e a auscultação pulmonar revelava murmúrio vesicular simétrico, com fervores dispersos bilateralmente. Não apresentava sopro tubar, sendo evidente uma tumefação, crepitante à palpação, na base da parede toraco-lateral esquerda, sugestiva de enfisema subcutâneo.

Analiticamente apresentava anemia $(\mathrm{Hb}: 8,8 \mathrm{~g} / \mathrm{dl}-$ normal: $11,5-16,5 \mathrm{~g} / \mathrm{dl})$ normocítica e normocrómica, linfopenia $\left(0,25 \times 10^{9} / \mathrm{L}\right.$ - normal: $\left.1,5-4,025 \times 10^{9} / \mathrm{L}\right)$ e hiponatrémia (128,6 mEq/L - normal: 135 - $145 \mathrm{mEq} / \mathrm{L})$, assim como proteína $C$ reativa moderadamente elevada $(11,3 \mathrm{mg} /$ $\mathrm{dl}$ - normal $<0,5 \mathrm{mg} / \mathrm{dl}$ ) e velocidade de hemossedimen-

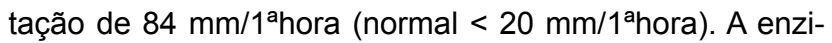
mologia hepática não evidenciava alterações. A radiografia torácica mostrava infiltrados heterogéneos bilaterais, mais evidentes na base esquerda (Fig. 2). No SU foi colhida uma amostra do pús, na qual foram identificados bacilos ácido-álcool resistentes (BAAR). O doente ficou internado no Serviço de Infeciologia com diagnóstico de tuberculose pulmonar fistulizada para a pele da parede torácica.

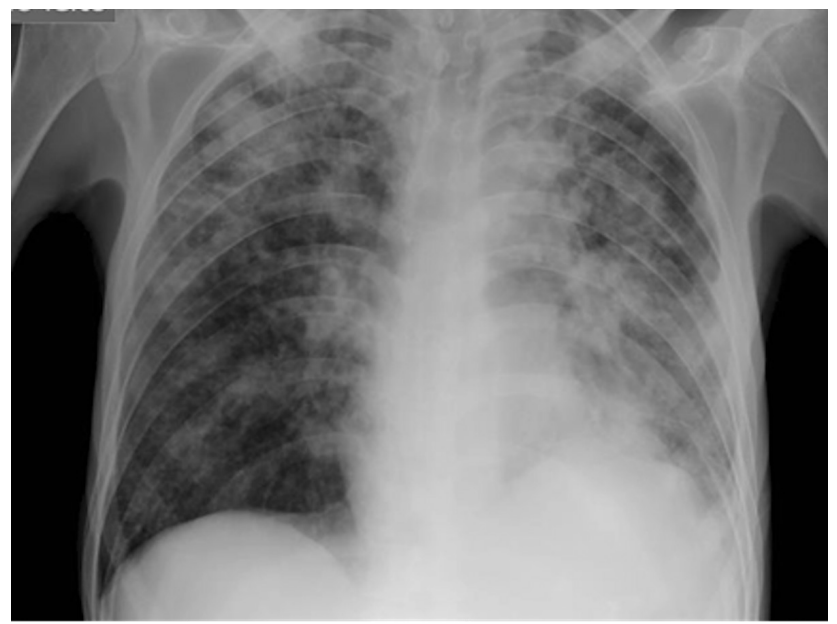

Figura 2 - Radiografia torácica mostrando infiltrado heterogéneo bilateral, mais evidente na base esquerda
Iniciou terapêutica antituberculosa quádrupla com Rifampicina (600 mg/dia), Isoniazida (300 mg/dia), Pirazinamida (1500 mg/dia) e Etambutol (1200 mg/dia) e durante o internamento realizou outros exames complementares para confirmação diagnóstica. A tomografia axial computorizada (TAC) torácica evidenciava 'múltiplas lesões cavitadas no pulmão direito, enfisema sub-cutâneo na base do hemitorax esquerdo e pequeno pneumotórax coletado na base torácica, correspondendo à fistulização cutânea' (Fig. 3). A pesquisa de bacilos ácido-álcool resistentes (BAAR) e a reação de polimerase em cadeia (PCR) para $M t$ foram positivas na expectoração e foi isolado $M t$ nas culturas (meio de Lowenstein / MGIT). Perante o exame cultural positivo foi efetuado teste de sensibilidade aos fármacos, não tendo sido identificadas resistências aos anti-bacilares de primeira linha. Do restante estudo, destaca-se a serologia negativa para VIH e hepatites víricas, assim como ausência de reatividade para Venereal Disease Research Laboratory (VDRL) (Tabela 1).

O doente esteve internado durante 30 dias, inicialmente em isolamento respiratório, sob terapêutica anti-bacilar e com plano nutricional individualizado. Os cuidados ao orifício de drenagem da fístula consistiram unicamente em

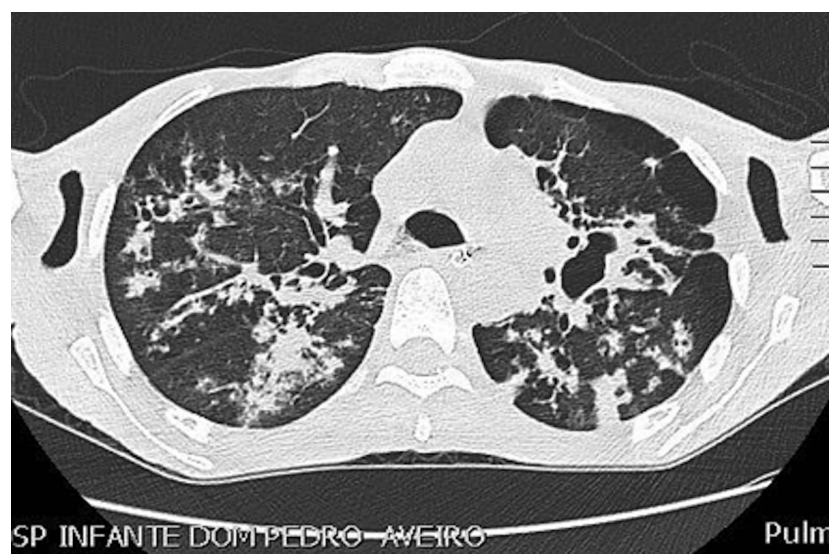

Figura 3 - TC- torácica com várias lesões cavitadas no pulmão direito, enfisema subcutâneo na base do hemitórax esquerdo e pequeno pneumotórax colectado nessa base, correspondendo à fistulização cutânea 
Tabela 1 - Resultados de serologias víricas e microbiologia

\begin{tabular}{ll}
\hline Ac VIH1+2 & Negativo \\
Ag HBs & Negativo \\
Ac VHC & Negativo \\
VDRL & Não reativa \\
Pesquisa de BK no pus & \\
- Exame directo & Alguns BAAR \\
Pesquisa de BK na expetoração & \\
- Exame directo & Muitos BAAR \\
- PCR & M. tuberculosis \\
- Culturas & M. tuberculosis
\end{tabular}

medidas conservadoras. Houve uma evolução clínica favorável, com diminuição da drenagem purulenta e encerramento progressivo do orifício fistuloso, o que ocorreu até ao final do internamento. De igual modo evoluiu com progressiva melhoria do estado geral, com alguma recuperação poderal, ainda que discreta (cerca de $2,5 \mathrm{Kg}$ ).

\section{DISCUSSÃO}

A tuberculose persiste como um problema major de saúde pública sendo depois da infeção pelo $\mathrm{VIH}$, a segunda causa mundial de morte por agente infecioso. ${ }^{5}$

$\mathrm{O}$ aparecimento do VIH levou a um aumento da sua incidência e apesar de estar geralmente confinada ao sistema respiratório pode envolver qualquer órgão, particularmente nos imunodeprimidos. ${ }^{6}$

No nosso doente a suspeita clínica de tuberculose era elevada. Nestes casos é recomendada a recolha de amostras orgânicas para exame direto e cultural. ${ }^{6}$ Perante a presença de um orifício fistuloso cutâneo, que veio a revelar-se uma fístula bronco-pleuro-cutânea, foram colhidas 3 amostras de expetoração e uma de conteúdo purulento da fístula. A coexistência de infeção pelo VIH foi também pesquisada e excluída.

A radiografia torácica continua a ser o principal método de imagem para a avaliação inicial, sendo a tomografia computorizada frequentemente solicitada para esclarecer uma imagem mais atípica, para melhor caraterizar uma tuberculose torácica já conhecida ou identificar possíveis complicações. $^{2}$

O caso que relatamos refere-se a um doente que apresentou ab initio uma fístula bronco-pleuro-cutânea, em consequência de tuberculose pulmonar ainda não tratada. A avaliação imagiológica por TC permitiu uma melhor

\section{REFERENCIAS}

1. Duarte R, Diniz A. Programa Nacional de Luta Contra a Tuberculose - Ponto da situação epidemiológica e de desempenho. Lisboa: DGS; 2013.

2. Jerrold JJ. Review: the immune response in human tuberculosis implications for tuberculosis control. J Infect Dis. 1997;176:1351-9.

3. Lung AN. Pulmonary tuberculosis: the essentials. Radiology. 1999;210:307-22.

4. Kim HY, Song K, Goo JM, Lee JS, Lee KS, Lim T. Thoracic sequelae and complications of tuberculosis. RadioGraphics. 2001;21:839-60.

5. WHO Global Tuberculosis Report 2013. Geneve: WHO; 2013.

6. Blumberg HM, Burman WJ, Chaisson RE, Daley CL, Etkind SC, Friedman LN, et al. American Thoracic Society/Centers for Disease Control and Prevention/Infectious Diseases Society of America: caraterização da localização e extensão da doença, identificando áreas infiltrativas parenquimatosas e cavitações nos lobos superiores, típicas de tuberculose pulmonar, assim como enfisema subcutâneo e pequeno pneumotórax coletado, correspondendo à área de fistulização.

Os relatos de casos de fístulas bronco-pleuro-cutâneas referem-se frequentemente a situações que surgem em consequência de cirurgia pulmonar, trauma torácico penetrante, empiema, abcesso pulmonar ou enfarte pulmonar maciço. Relatos ocasionais associam estas fístulas a infeções por Histoplasma ou Aspergillus, na presença de empiema. ${ }^{7}$ Outra entidade que deve ser considerada é a actinomicose pulmonar.

A associação entre $M t$ e o desenvolvimento de fístula bronco-pleuro-cutânea na ausência de empiema é rara, não existindo recomendações relativas ao seu tratamento. O único caso relatado na literatura foi descrito em 2011, tendo sido adotada uma abordagem com terapêutica anti-bacilar clássica, com encerramento da fístula sem recurso a outras estratégias terapêuticas, ${ }^{8}$ conforme verificado no caso presente.

Encontram-se descritos casos de encerramento por abordagem cirúrgica ou endoscópica, com técnicas minimamente invasivas em fístulas bronco-pleuro-cutâneas associadas a lobectomia, trauma ou aspergilose, na presença de empiema. ${ }^{9,10}$ A referenciação para Cirurgia Cardio-torácica foi ponderada mas as estratégias invasivas não foram necessárias pela boa evolução clínica, tendo-se revelado o controlo do foco infecioso de primordial importância na sua resolução.

Em conclusão, a TP é uma doença sobejamente conhecida, mas algumas das suas complicações e sequelas são bastante raras, particularmente nos dias de hoje e em países industrializados. Deste modo, sendo a tuberculose ainda frequente no nosso país, este caso ilustra uma forma atípica e rara desta patologia que, após diagnóstico e terapêutica médica dirigida, apresentou evolução favorável.

\section{CONFLITOS DE INTERESSE}

Não há conflitos de interesse para cada um dos autores.

\section{FONTES DE FINANCIAMENTO}

Não foi atribuída nenhuma bolsa ou subsídio para a realização do presente trabalho.

treatment of tuberculosis. Am J Respir Crit Care Med. 2003;167:603-62.

7. Johns LE, Garrison RG, White GT. Bronchopleurocutaneous fistula due to infection with Histoplasma capsulatum. Chest. 1973;63:638-41.

8. Siddiqui MA, Shameem M, Akhtar J, Baneen U, Bhargava R, Ahmed Z, et al. Bronchopleurocutaneous fistula in absence of empyema: a rare presentation of pulmonary tuberculosis. Lung India. 2011; 28: 72-3.

9. Jain R, Baijal SS, Pandey CK, Saraswat VA. Endobronchial closure of a bronchopleural cutaneous fistula using angiography catheters. AJR Am J Roentgenol. 2000;175:1646-8.

10. Snell GI, Holsworth L, Foeler S, Eriksson L, Reed A, Daniels FJ, et al. Occlusion of a broncho-cutaneous fistula with endobronchial one-way valves. Ann Thorac Surg. 2005;80:1930-2. 
Ana Sofia JOSÉ MONTEZ, Daniel COUTINHO, Jorge VELEZ, Filomena FREITAS, Célia OLIVEIRA

\section{Fístula Bronco-Pleuro-Cutânea: Uma Manifestação Rara de Tuberculose Pulmonar}

Acta Med Port 2015:28:260-262

Publicado pela Acta Médica Portuguesa, a Revista Científica da Ordem dos Médicos

Av. Almirante Gago Coutinho, 151

1749-084 Lisboa, Portugal.

Tel: +351218428 215

E-mail: submissao@actamedicaportuguesa.com

www.actamedicaportuguesa.com

ISSN:0870-399X | e-ISSN: 1646-0758

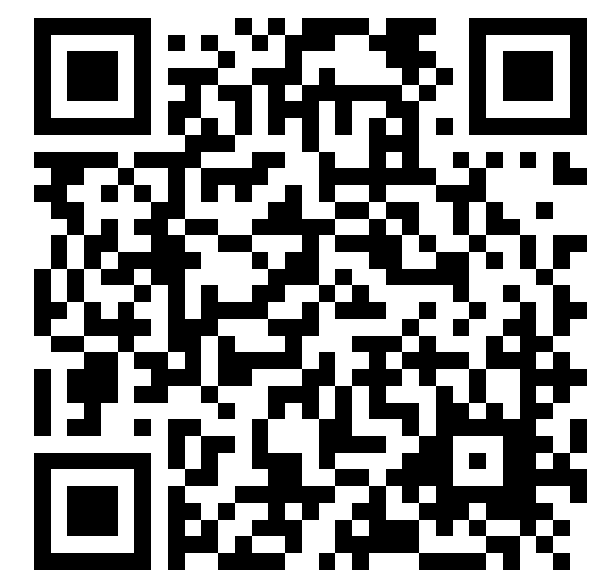

